\title{
Workers' compensation claims for occupational tuberculosis in South African health workers: Outcomes and workers' experiences
}

\author{
${ }^{1}$ School of Public Health and Family Medicine, Faculty of Health Sciences, University of Cape Town, South Africa \\ ${ }^{2}$ School of Population and Public Health, Faculty of Medicine, University of British Columbia, Vancouver, Canada
}

N van de Water, ${ }^{1}$ MB ChB, MMed, FCPHM (SA) (Occ Med); A Yassi, ${ }^{2}$ MD, MSc, FRCPC; R Ehrlich, ${ }^{1}$ MB ChB, FCPHM (SA) (Occ Med), PhD

Corresponding author: R Ehrlich (rodney.ehrlich@uct.ac.za)

Background. Given the elevated risk of tuberculosis (TB), including drug-resistant disease, experienced by health workers in South Africa (SA), effective workers' compensation for occupational TB is a legal right and an essential social benefit.

Objectives. To investigate the experience of the workers' compensation system among health workers who suffered from TB while working in public service facilities in Western Cape Province, SA.

Methods. In this case series with a qualitative component, 300 claims for occupational TB in health workers were sampled from the provincial health department database of claims submitted. Claim status for each case was ascertained. An attempt was made to contact each health worker for a telephonic interview consisting of both closed- and open-ended (qualitative) questions. Fifty-one interviews were completed. Results. In nearly half of the cases, there was no record of claim status on the state Compensation Fund website. Of the 51 interviewees, only one had received all the compensation benefits for their particular claim circumstances. Health workers' experience of having their cases reported for compensation purposes was marred by perception of poor communication and administration. The experience of contracting TB was further characterised by surprise, perceptions of stigma, financial burden and ongoing ill-health.

Conclusions. Affected health workers' experience of the workers' compensation system was mostly negative, adding to the burden of being ill with TB. Education of management and clinicians, improvement in communication, and timeous and regular checking of claim status and of payment of applicable compensation are required at the provincial level. Dedicated facility-based occupational health units are needed, with a staff complement of knowledgeable persons trusted by their colleagues. However, the effectiveness of the system is ultimately dependent on the ability of the Compensation Fund to register and display claims timeously and administer compensation expeditiously.

S Afr Med J 2020;110(5):389-395. https://doi.org/10.7196/SAMJ.2020.v110i5.14247

Health workers in South Africa (SA) have a risk of tuberculosis (TB) two to three times that of the general population. ${ }^{[1]}$ The high burden of HIV infection and drug-resistant TB further increases the risk, morbidity and mortality of occupational TB. ${ }^{[2,3]}$ The Compensation for Occupational Injuries and Diseases Act ${ }^{[4]}$ (COIDA) covers 'infectious or parasitic diseases contracted in an occupation where there is a particular risk of contamination'.

Health workers who are diagnosed with $\mathrm{TB}$ and who work in a setting involving exposure to Mycobacterium tuberculosis are presumed to have an occupational or compensable disease (the 'rule of presumption' - internal circular no. H/34/2004 dated 26 March 2004 from the head, Department of Health, Provincial Government of the Western Cape, entitled 'Compensation for Occupational Injuries and Diseases Act, 1993 (Act No. 130 of 1993): Reporting of tuberculosis of the lungs in health care workers'). ${ }^{[5]}$ This rule of presumption represents a progressive benefit, at least on paper, for SA health workers. Occupational tuberculosis is the most frequently reported infectious disease among health workers in SA (Milly Ruiters, chief director, Compensation Fund - Powerpoint presentation to the South African Society of Occupational Medicine, Durban, 25 November 2017).

The benefits of having a claim accepted for an occupational disease are summarised in Table 1. ${ }^{[6]}$ 'Employee' is defined under the COIDA as any person who has a contract of service with an employer, and includes apprenticeships and staff provided by a labour broker. While the COIDA Commissioner remains responsible for adjudication of cases, the Western Cape Department of Health (WCDH), like all provincial employers, is classified as an 'exempted employer' - it pays no premiums, but is responsible for funding benefits provided to its employees under the Act. ${ }^{[6]}$ The $\mathrm{WCDH}$ in addition provides benefits to its employees beyond those under the COIDA. These include full salary (including commuted overtime) while on leave for any occupational disease or injury ('occupational leave') and, with approval, free medication for the condition from provincial facilities after the mandatory closure of COIDA claims 24 months post diagnosis.

In general, the workers' compensation system has been shown to be burdened with many flaws. ${ }^{[7-19]}$ There is under-reporting of occupational diseases, which is an employer responsibility (that requires disclosure by the employee). Failure of the employer and/ or the treating practitioner to follow required procedures, including submitting all forms and reports timeously and accurately, is another barrier. Problems identified at the Compensation Fund include failure to register claims (which may include losing documents), nonresponse to inquiries, slow progression from one stage to the next, and inadequate assessment of impairment on the basis of which permanent disablement is awarded. Health workers who develop occupational TB may therefore not receive the benefits to which they are entitled. To the authors' knowledge, only one study has previously examined workers' compensation of health workers for occupational TB. ${ }^{[1]}$ 
Table 1. Benefits to employees claiming for compensation for occupational $\mathrm{TB}^{\left[{ }^{[6]}\right.}$

\begin{tabular}{ll}
\hline Benefit & Allowance under the COIDA \\
\hline $\begin{array}{l}\text { Temporary disablement } \\
\text { ('occupational leave') }\end{array}$ & $\begin{array}{l}\text { 75\% of normal wage while } \\
\text { convalescing and not at work, no } \\
\text { deducted from normal sick leave }\end{array}$ \\
$\begin{array}{l}\text { Payment of medical } \\
\text { expenses }\end{array}$ & $\begin{array}{l}\text { Payment of reasonable medical } \\
\text { expenses where out-of-pocket } \\
\text { expenses occur }\end{array}$
\end{tabular}

Explanation of benefit

While ordinary sick leave is generally paid in full, a capped number of days are available, after which unpaid leave would have to be taken. The COIDA benefit allows for longer rehabilitation or recuperation periods away from work, as well as preservation of sick leave days available.

Employees are entitled to consult either a state medical practitioner at no cost for TB diagnosis and treatment, or a private medical practitioner where they will initially be liable for costs incurred, including for medication (either personally or through medical aid schemes). Invoices can be submitted to the WCDH for reimbursement. While costs may be covered by medical aid schemes, limits on specific categories of medical service may apply, reducing the employee's cover for other medical services in that calendar year.

Compensation for permanent disablement
Compensation based on level (percentage) of impairment assessed $^{[20]}$
A case is finalised with an examination and lung function 12 months after the completion of treatment or where the physician considers that no further improvement is expected. An impairment percentage is assigned to the claim by the Compensation Fund based on lung function, medical report and radiological examinations where necessary.

\section{Objectives}

To investigate the experiences of health workers whose cases of occupational TB were reported via the WCDH to the Compensation Fund. Specific objectives were: $(i)$ to measure the efficiency of the workers' compensation process, i.e. timeous completion of all components from submission to resolution (repudiation or payment); and (ii) to document their experience of the system, including accessibility of the process. A third objective was added: to understand the effect of a health worker's diagnosis of TB on their work and their experiences in the workplace.

\section{Methods}

\section{Design, setting and participants}

This study was a case series with a qualitative component. The database held by the Directorate: People Practices and Administration (hereafter 'Directorate') in the WCDH, containing details of cases submitted to the Compensation Fund, was used. Using the Excel function, 2013 version (Microsoft, USA), all cases within the period 1 January 2003 - 31 December 2016 were randomly assorted and the first 300 cases selected. We aimed to interview 100 health workers. Using details available to the WCDH, an attempt was made to contact each sampled health worker for a telephonic interview. All health workers who consented telephonically were interviewed.

\section{Data collection}

The process within the WCDH by which a case of occupational $\mathrm{TB}$ is diagnosed and reported as an occupational disease to the Compensation Fund is shown in Fig. 1. Claims are prepared by the facility or the treating practitioner and are registered by the Directorate. They are returned to the submitting practitioner if incomplete, otherwise submitted to the Compensation Fund. From 2003 to mid-2014, claims were submitted by post. From mid-2014 the claim was submitted directly on the Umehluko electronic system. In all cases, hard copies were kept. Sickness absenteeism details are captured from the relevant human resources (HR) office only once a claim number has been received from the Fund.

Data collection in the study followed a two-step process, co-ordinated by the first author.
1. General and claim status information on the main sample was obtained from three sources: (i) information on the Directorate database; (ii) records from the WCDH HR head office; and (iii) the Department of Labour web portal for accessing the status of COIDA claims.

2. Health workers in the interview sample were contacted telephonically by the interviewers to answer a questionnaire consisting of both closed- and open-ended (qualitative) questions.

The HR office was requested to provide contact information and job title. HR personnel were not told the purpose of the study. Leave data were obtained from the Directorate on claims for which a claim number had been assigned. The Compensation Fund web portal on claims status (https://claimstatus.labour.gov.za) was accessed: in order to access claim status, a minimum of identity number, claim number, or surname and date of injury/disease diagnosis are needed.

Questionnaires were pre-populated in the first section with contact information and were shared via unique web links with the assigned interviewers. Following the consent section, questions covered three subjects:

1. Experience regarding the compensation benefits available for people contracting an occupational disease: (i) reimbursement of medical expenses; (ii) temporary disablement (occupational leave); and (iii) permanent disablement payments.

2. Experience regarding the process of having the case reported as an occupational disease to the Compensation Fund.

3. Experience as a health worker of having developed TB.

The four interviewers attended a joint training session and were thereafter randomly allocated blocks of 10 participants. A maximum of three attempts to contact each person telephonically were made. On initial contact, participants were given the opportunity to decline, schedule another time or continue with the interview after providing consent for participation and the recording of calls. All participants were able to understand and answer the questions in either English or Afrikaans, and selected their preferred language of the two. Calls were recorded digitally in order to ensure accurate capture of openended answers. With regard to leave taken, the different types of leave 


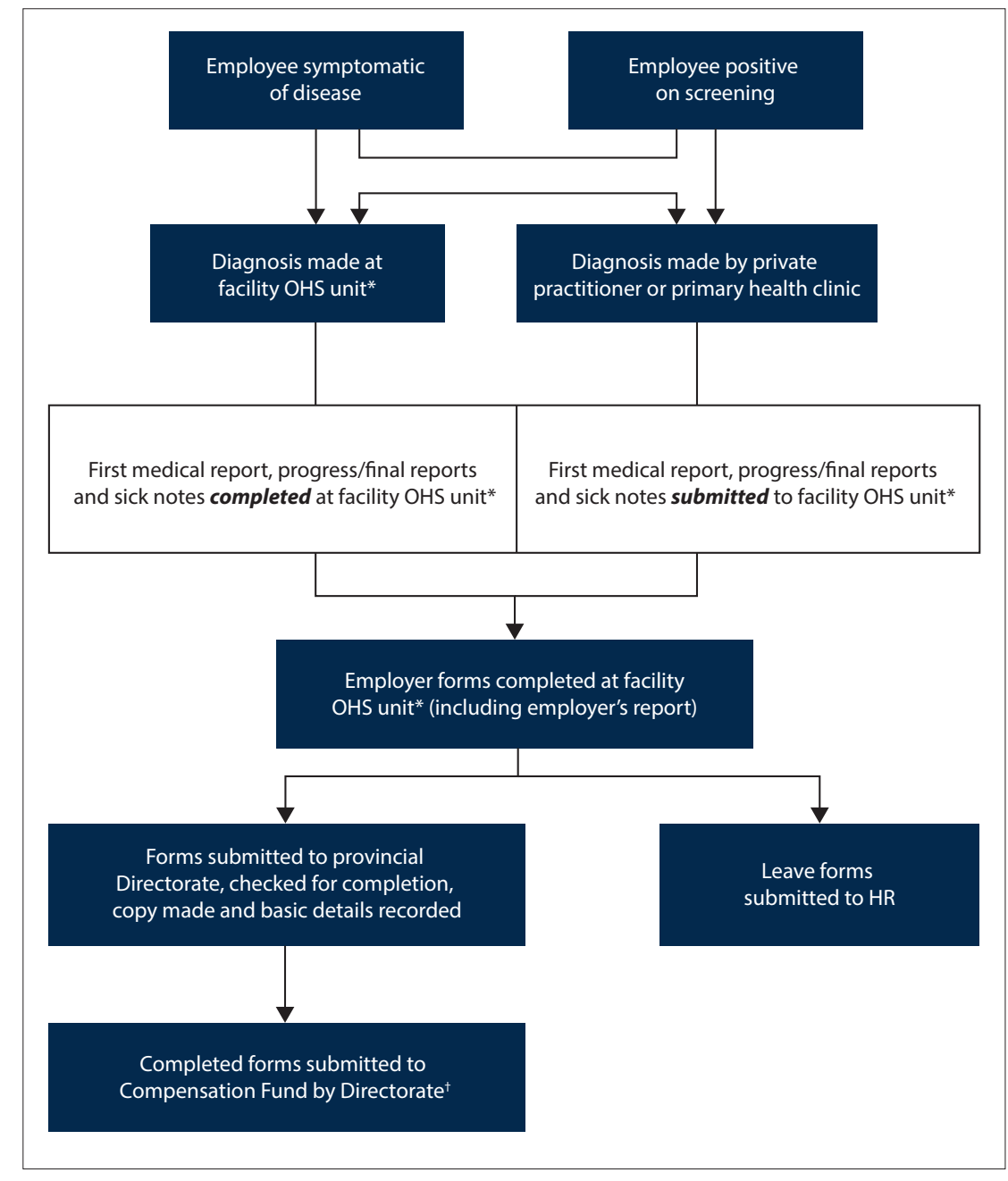

Fig. 1. Process for the submission of a claim for occupational tuberculosis. (OHS = occupational health and safety; HR = human resources; ${ }^{*}$ Facility $\mathrm{OHS}$ units are only available in larger hospitals, and where they are not available, the alternative route for diagnosis is used and employer forms are completed by the employee's relevant HR office; ${ }^{\dagger} B y$ post, 2003 - 2013, and on Department of Labour electronic system from 2014.)

were explained by the interviewer. A pilot study conducted with five randomly selected health workers whose claims were dated prior to 2003 resulted in minor edits to the questionnaire and consent process.

\section{Statistical and qualitative analysis}

A descriptive analysis of the general information available from the main sample of 300 health workers was undertaken to explore the patterns of case characteristics and claim status. The average waiting period for claims still unresolved was calculated from date of diagnosis until the final date of checking claim status (31 December 2017) while excluding those cases where resolution had occurred, as information on date of resolution was not available. Where relevant information was missing from the database, that case was excluded in the analysis of that particular field. This data analysis was conducted using the Stata statistical package version 13 (StataCorp, USA).

Narrative data for all open-ended questions were examined by two members of the research team, including a psychologist experienced in qualitative research. This analysis was done manually, and themes were placed under two main headings: (i) the health worker's experience regarding the reporting of their occupational TB; and (ii) their experience of having $\mathrm{TB}$ and its resultant effect on their working life. The researchers compared analyses and compiled one set of themes. These were judged to have reached saturation.

\section{Ethics approval and informed consent}

The study protocol was reviewed and approved by the Human Research Ethics Committee of the Faculty of Health Sciences,
University of Cape Town (ref. no. HREC 242/2017). Further approval was obtained from the WCDH. Telephonic consent was obtained from each interviewee.

\section{Results \\ Main sample \\ Demographic and claim status \\ characteristics}

As seen in Table 2, most cases were women $(n=220 ; 77 \%)$, and approximately half were nurses $(n=135 ; 52 \%)$. The median age was 39 years (range $30-48$ ). There was sufficient prior information to check 288 claims on the Compensation Fund website. Of the claims submitted by post (2003 to mid-2014), 52/202 (26\%) had no record found by the end of 2017. Of those submitted electronically (mid2014 to 2016), 79/86 (92\%) lacked a Fund record. For cases that had not had resolution with either acceptance or repudiation of the claim, i.e. 'still waiting' cases, the median (interquartile range (IQR)) waiting period from date of submission to 31 December 2017 was $5.8(3.2-9.2)$ years.

\section{Location, type of TB and leave}

Nearly half of the cases were initially reported at tertiary hospitals $(n=137 ; 46 \%)$, staffed by approximately a third of WCDH employees. There were 2 cases of extrapulmonary $\mathrm{TB}$ and 11 cases of multidrug-resistant $\mathrm{TB}$ (3.7\%). Leave data on record at the Directorate $(n=181)$ showed a range of $1-492$ days' leave (median 24).

\section{Interview sample}

Contact information received from HR was available for only 205 of the 300 main sample cases. A further 153 health workers were not interviewed owing to failed telephonic contact $(n=81)$, declined participation $(n=11)$, and end of the 3-month period assigned to interviewing. One interview terminated prematurely, leaving 51 completed interviews (51\% of the target) (Fig. 2).

\section{Leave}

Only 3 interviewees reported not having taken sick leave as a result of their TB (Table 3). The median (IQR) reported duration of self-reported leave was 4 (2 8) weeks (range 0 - 96 weeks). Half of the interviewees who took sick leave $(n=25$; $52 \%)$ reported accessing occupational leave only. A further 9 participants (19\%) used combinations of normal sick leave, annual leave, prolonged incapacity leave and unpaid leave in addition to their occupational leave. The remainder $(n=14 ; 29 \%)$ did not recall accessing any occupational leave and made 
Table 2. Demographic characteristics of health workers with submitted claims for occupational TB

\begin{tabular}{|c|c|c|}
\hline Variable & Sample not interviewed $(N=249)$ & Sample interviewed $(N=51)$ \\
\hline Sex, $N$ & 237 & 50 \\
\hline Male, $n(\%)$ & $55(23)$ & $12(24)$ \\
\hline Female, $n(\%)$ & $182(77)$ & $38(76)$ \\
\hline Age at diagnosis (years), median (IQR) & $39((30-47)$ & $36(32-45)$ \\
\hline Job category, $N$ & 209 & 51 \\
\hline Allied health professionals, $n(\%)$ & $16(8)$ & $5(10)$ \\
\hline Medical doctors, $n(\%)$ & $25(12)$ & $7(14)$ \\
\hline Support staff, $n(\%)$ & $60(29)$ & $12(24)$ \\
\hline Nurses, $n(\%)$ & $108(52)$ & $27(53)$ \\
\hline Claim status, ${ }^{*} N$ & 238 & 50 \\
\hline No record found, $n(\%)$ & $103(43)$ & $28(56)$ \\
\hline Open, $n(\%)$ & $12(5)$ & $5(10)$ \\
\hline Registered not adjudicated, $n(\%)$ & $47(20)$ & $5(10)$ \\
\hline Claim repudiated, $n(\%)$ & $4(2)$ & 0 \\
\hline Claim accepted, $n(\%)$ & $72(30)$ & $12(24)$ \\
\hline
\end{tabular}

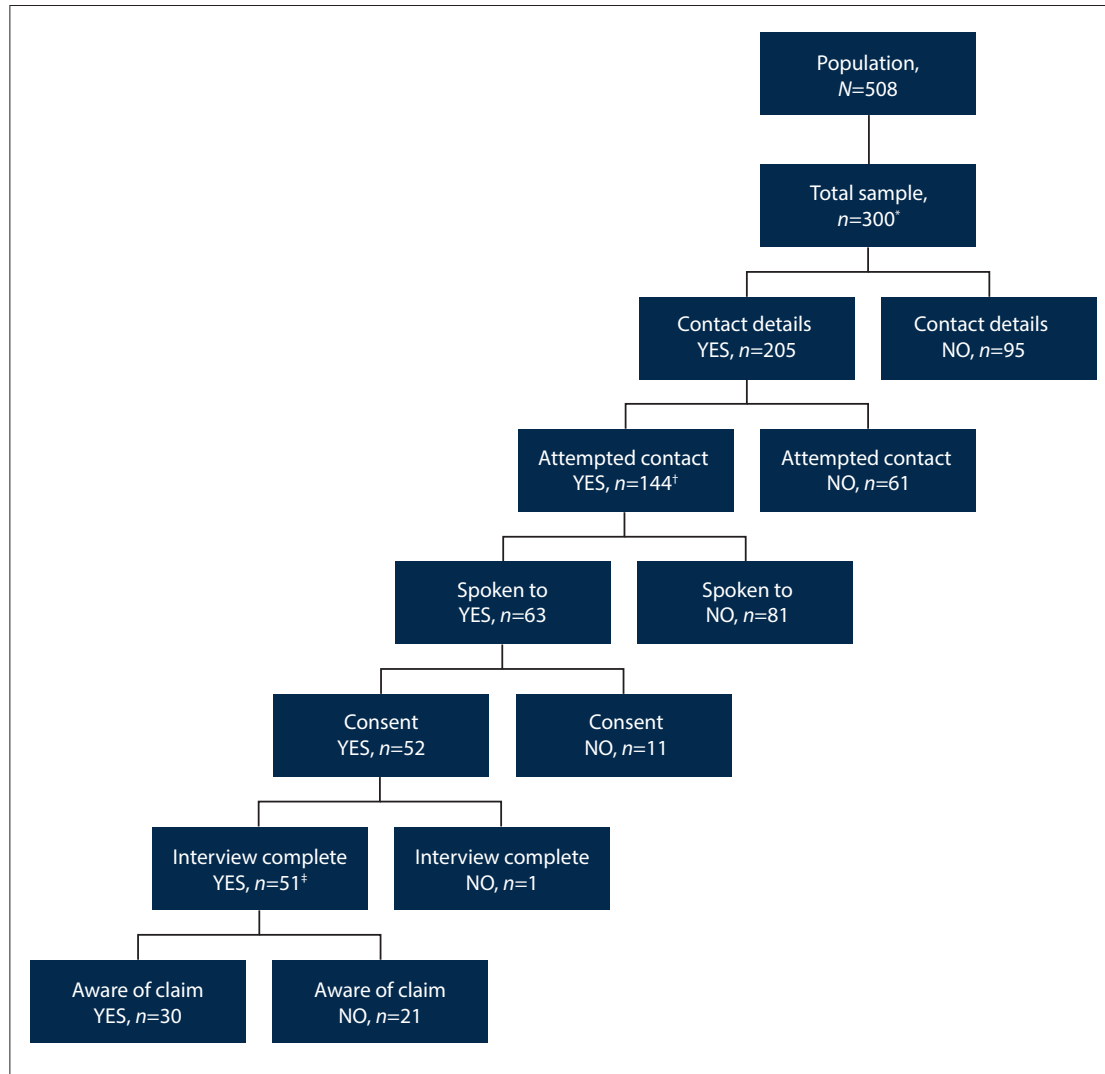

Fig. 2. Participation flow from sampling to interviews. $\left({ }^{*}\right.$ Main sample; ${ }^{\dagger}$ Number of health workers with contact details available and attempted contact by interviewers; ${ }^{*}$ Interview sample.)

use of alternative leave options. In 2 cases interviewees did not receive a full salary, and overtime pay was withheld; neither had accessed occupational leave.

\section{Reimbursement of medical expenses}

Of the 39 participants (76\%) who incurred personal medical expenses related to their occupational TB, 28 had expenses that were not covered by their private medical aid (Table 3). These expenses were mainly incurred prior to diagnosis and in the diagnostics work-up. Six participants purchased medication at their own cost and 2 paid for their own physiotherapy. None of the participants who had bills submitted for reimbursement under the COIDA had received payment at the time of the interview.
Compensation for potential permanent disablement

Most participants $(n=41 ; 80 \%)$ reported having had some form of examination after the completion of their medication (Table 3). Ongoing health problems (related to TB) reported by $21(42 \%)$ of the participants included (in decreasing frequency) shortness of breath, malaise, chest pain, recurrent chest infections, peripheral neuropathy, ongoing cough, impaired lung function, wheezing and haemoptysis. One participant required a partial lobectomy and was receiving ongoing monthly compensation for permanent disablement under the COIDA.

\section{Experience of reporting}

Only interviewees who were actually aware of a claim were questioned on the reporting process ( $n=30)$ (Fig. 2). Half of these participants had reported at a staff occupational health clinic $(n=15)$, with the remaining claim processes initiated by their facility or unit manager $(n=7)$, HR manager $(n=4)$ or diagnosing doctor $(n=2)$. Two were unable to recall the route. Of the 9 who believed that their claims had definitely been submitted by the province to the Compensation Fund, 3 had received written communication in that regard, 3 had followed up on their own accord, and the rest had been assured of this by their HR practitioner.

The following themes were identified from open-ended questions.

\section{Health workers' experience of the} reporting process

'I didn't hear anything'

Communication around the compensation process was very poor. In most instances, 
Table 3. Closed-ended questions on interview of health workers $(N=51)$ with submitted claims for occupational $\mathrm{TB}^{*}$

\begin{tabular}{|c|c|c|}
\hline Variable & Yes & No \\
\hline \multicolumn{3}{|l|}{ Incapacity leave } \\
\hline Did you take sick leave? $n(\%)$ & $48(94)$ & $3(6)$ \\
\hline How long was your leave (weeks)? $(N=48)$, median (IQR) & $4(2-8)$ & \\
\hline Did you receive full earnings while on leave? $(N=49), n(\%)$ & $47(96)$ & $2(4)$ \\
\hline \multicolumn{3}{|l|}{ Medical expenses, $n(\%)$} \\
\hline Did you incur cost related to your TB? & $39(76)$ & $12(24)$ \\
\hline Did you pay for this on your own? $(N=39)$ & $28(72)$ & $11(28)$ \\
\hline Did you submit these bills for reimbursement? $(N=38)$ & $15(39)$ & $23(61)$ \\
\hline Were you reimbursed? $(N=15)$ & 0 & $15(100)$ \\
\hline \multicolumn{3}{|l|}{ Permanent incapacity, $n$ (\%) } \\
\hline Were you advised to have a final examination? & $28(55)$ & $23(45)$ \\
\hline Did you have any examination after treatment? & $41(80)$ & $10(20)$ \\
\hline Do you have any continuing health problems? $(N=50)$ & $21(42)$ & $29(58)$ \\
\hline Did you receive any compensation payment? $(N=50)$ & $1(2)$ & $49(98)$ \\
\hline \multicolumn{3}{|l|}{ Experience of reporting occupational TB $(N=30), n(\%)$} \\
\hline Did you receive any communication from the province regarding your claim? & $3(10)$ & $27(90)$ \\
\hline Are you aware of whether your case was actually submitted to the compensation commissioner? & $9(30)$ & $21(70)$ \\
\hline Did you feel victimised in any way by having your case reported for COIDA purposes? & $7(23)$ & $23(77)$ \\
\hline \multicolumn{3}{|l|}{ Experience of having TB as a HW and its effect on working life, $n(\%)$} \\
\hline Did you feel victimised in any way by having been diagnosed with TB as an $\mathrm{HW}$ ? & $23(45)$ & $28(55)$ \\
\hline Was your work affected by your diagnosis of TB? & $18(35)$ & $33(65)$ \\
\hline Are you in the same facility you were in at diagnosis? & $37(73)$ & $14(27)$ \\
\hline
\end{tabular}

participants were not provided with information on what benefits were available when reporting ('they just made me sign forms' porter). Others felt overwhelmed by the information and that 'being told about any type of illness is a shock' (medical specialist). Interviewees suggested that information should be given in parts with follow-up sessions.

Negative sentiments were expressed towards the compensation system (' $[\mathrm{I}]$ just left everything' - nurse). Processes and documentation were 'laborious' (medical doctor). Resentment of the requirement to settle medical bills and submit for reimbursement was expressed.

'No special place for staff, no empathy, no support'

The need for a designated place for staff to report their cases was identified. Those on night duty were not able to attend the occupational health clinic. One female nurse stated that she did not have any access to an occupational health clinic and had to utilise a casualty department where she felt she was not given due attention.

A lack of empathy from caregivers was perceived ('They keep asking me questions as if I am the one who is stubborn' - household aid; '... made me feel like criminal. Interrogate me ...' - nurse). The lack of dedicated, knowledgeable support staff led to strained relations with managers. A perceived lack of understanding and support from managers was expressed ('the support of my supervisors weren't there' - nurse).

\section{Experience of having TB and its effect on working life}

Of the 18 participants (35\%) who reported that their work had been affected by the diagnosis of TB (Table 3), 5 had changed jobs or facilities as a direct result of their TB. Of a further $9(18 \%)$ who had changed job or facility, 4 gave career progression as the reason and the remainder other reasons. Just under half of the participants $(n=23$; $45 \%$ ) believed that they had been 'victimised' or 'made to feel bad' by being diagnosed with TB.

\section{'It's all my fault'}

Various negative emotions as a result of acquiring TB as a health worker were expressed, many in reference to the responses of other people ('I was embarrassed and ashamed' - emergency worker; 'I felt like I was being punished' - radiographer; 'My people [children/ family] looked at me differently ... at home I was scared that the children would touch me' - porter; 'When I was diagnosed people distanced themselves from me' - nurse; 'They would say: "Oohh, pass that one, because he has TB now"' - emergency worker).

As a consequence of emotions like these, one participant reported concealing her diagnosis of TB from her colleagues for fear of social isolation.

\section{'Never expected to have TB'}

Participants' surprise that they had contracted TB was a prominent theme. They reported a view among co-workers to the effect 'that they [health workers] will not get TB' (medical doctor), and naivety both in the community and among health workers about the risk of contracting TB. Participants did not know where they had contracted $\mathrm{TB}$, especially if they had taken precautions ('I am still wondering how I picked it up especially being so cautious' - radiographer).

\section{'Sick as a dog'}

Interviewees reported struggling to perform their duties as usual owing to effects of the TB and side-effects of the medication ('I did not feel my normal self' - radiographer). Concern was expressed about their infectiousness in the ward where they worked. More consistently however, participants were concerned about their future exposure and possible re-infection ('I do not want to get TB again so I moved ...'- registrar). Two participants stated that they had resigned in order to protect their health. Lastly, there was a general perception that colleagues were burdened by the participant's disease ('It affected them more than me' - medical specialist). 


\section{Discussion}

To our knowledge, this study is the first to examine the personal experiences of the workers' compensation system among health workers who have both been diagnosed with TB while in service and had their condition reported to the Compensation Fund as an occupational disease. We detected a number of deficiencies in the process.

\section{Processing of COIDA claims for occupational TB}

In $46 \%$ of the submitted claims, 'no record found' was indicated on the Compensation Fund website. This ranged from $26 \%$ of older claims submitted by post to $92 \%$ of more recent claims (2014 - 2016) submitted on the electronic system. All claims reported to and submitted by the WCDH Provincial Directorate should reflect on the Compensation Fund website as being 'registered not adjudicated' or 'open', indicating that they have been received and are being processed, irrespective of document completeness. This lack of registration, capturing and/or display of claims by the Compensation Fund and the inference of poor progression of claims have been noted previously. ${ }^{[7,10,14,17]}$ For example, in a series of occupational skin disease claims submitted to the Compensation Fund by the National Institute for Occupational Health between 2007 and 2010, 29/57 (51\%) were assessed in a retrospective review as 'not received or no record of being received', very similar to our overall finding. ${ }^{[17]}$

Recommendations on improving the functioning of the Compensation Fund, including prescriptive findings by the Public Protector, have been made many times over past decades. ${ }^{[7,9,15,16]}$ Given its employer responsibilities as a major client, the WCDH should be putting pressure on the Fund to improve its administrative processes. (The Directorate has embarked on a process of engagement with the decentralised Department of Labour office to pursue outstanding occupational TB claims, with some success. For example, some of the claims were assessed and finalised by a visiting medical officer from the Compensation Fund. However, a number of claims remain unfinalised. Personal communication, Mr D Kannemeyer, senior personnel officer, Provincial Directorate, 29 August 2019.) Poor servicing by the Compensation Fund is likely to aggravate underreporting of occupational disease by employees and employers. ${ }^{[7]}$

Regarding the claims that were submitted by the WCDH, it was expected that more cases of extrapulmonary TB would have been reported. The Compensation Fund's internal Circular (guidance) Instruction (No. 178) on the diagnosis of occupational TB and submission of a claim covers only pulmonary TB ${ }^{[20]}$ However, the Instruction was published in 2003, prior to the latest (2004) revision of the list of occupational diseases, which does not restrict compensation to pulmonary disease. ${ }^{[4]}$ A number of problems with the Instruction and the likely confusion among healthcare providers managing health workers with TB (and by implication among the staff of the Compensation Fund) have been described previously. ${ }^{[11]}$ The Instruction needs to be updated to be aligned with the above revised wording in the Act. Furthermore, clear guidelines and training on what to do if diagnosing or managing a case of employee $\mathrm{TB}$ should be provided in each province for employees, managers and private providers.

Frustration was expressed by participants at the lack of communication from the provincial office with regard to the progress of their claims. Inadequate communication contributes to lack of confidence in the employer's administration and is likely to hinder reporting. While poor communication from the Compensation Fund ${ }^{[7,15,16,19]}$ is clearly an upstream component, the WCDH needs to improve its own internal administrative processes, particularly routine and regular follow-up of claims (see personal communication, Mr D Kannemeyer, above). Affected employees should be counselled about benefits, particularly the meaning of occupational leave, continuity of salary and the right to have medical expenses reimbursed.

Financial burden was one of the themes emerging from the open-ended responses and has been noted in previous reports. ${ }^{[7,9,19]}$ Treatment for $\mathrm{TB}$ is free in the state sector. However, most participants reported out-of-pocket expenses for the diagnosis and management of their $\mathrm{TB}$, and a number had sought private medical care. A significant minority reported post-TB treatment ill-health or impairment. Claims should not be 'finalised' until the medical practitioner is satisfied that maximum medical improvement has been reached. This may post-date the end of treatment. The lack of access to compensation by participants with ongoing ill-health following the end of treatment suggests a failure of post-treatment clinical evaluation and/or failure of care providers to support workers' compensation processes in the post-treatment stage. Education is needed so that practitioners, whether in the private or public sector, understand this specific role of the COIDA in such cases.

Previous research has found that health workers have a preference for an on-site occupational health unit that can provide confidential, no-cost services with minimal waiting times. ${ }^{[21]}$ Views expressed in this study supported the value to employees of knowledgeable staff and a service experienced as trustworthy and empathetic. Confidentiality fears were not prominent, possibly because claim submission is a required medicolegal process. Such a unit should support claims submission, maintain contact with the employee, educate and support affected employees, and undertake the required post-treatment examinations. One obstacle to reporting in some cases was the employee's location and lack of access to existing occupational health facilities. While having 24 -hour dedicated units is not feasible, a telephonically on-call staff member could assist employees needing advice on occupational injuries and diseases.

\section{Health workers' experience of TB}

The particular stresses of health workers' experience of contracting occupational TB are well documented. ${ }^{[22-25]}$ Prominent among these experiences is stigma perceived by such health workers. ${ }^{[23,24,26,27]}$ It was reflected in this study, as evidenced by the quotes above. Stigma has a negative effect on health workers' willingness to utilise occupational health units, seek treatment or disclose their diagnosis. ${ }^{[23,24,27]}$ Reduction of stigma requires interventions at community, policy and organisational levels in addition to education of health workers that specifically addresses attitudes and fears. ${ }^{[23,24,27,28]}$

Participants reported surprise at contracting TB, in some cases because they believed that 'adequate precautions' had been taken, in others simply because they perceived their risk as low. Perceptions of personal TB risk vary according to occupational status, specific training and exposure to TB infection control practices, although awareness of high risk is not necessarily associated with a high degree of TB infection control practice. ${ }^{[24,29,30]}$ As with stigma, interventions at different levels are needed for health workers to fully understand their risk of TB, including innovative approaches such as personal narratives and group drama, which go beyond the sharing of factual information on TB. ${ }^{[24,31,32]}$

\section{Study limitations}

The province does not keep a central record of employees who have had TB. Missing from this study is the experience of health workers who chose not to report their TB to the employer, or those whose treating clinician, line manager or HR officer failed to do so, whether due to lack of awareness of COIDA provisions or a desire to 
protect the patient's privacy. The study was therefore limited to those employees who had had a COIDA process initiated and recorded on a submission database.

The two groups that made up most of the interview 'non-responses' were those with whom telephonic contact could not be made and those who were not interviewed because the interview phase ran out of time. Their omission may have produced some bias in the sample, although the effect is difficult to evaluate. There may also have been fall-off in accurate recall of claims dating from 2003. Features that suggest validity of the findings are a relative consistency in the reports of participants, with saturation of information emerging in later interviews, and coherence of the findings with those of other studies of the compensation system.

Reasons for claims not being displayed on the compensation authority's web portal were not investigated in this study. However, the high proportion of claims submitted electronically that 'failed' to register reflects problems with the electronic system for capturing occupational disease claims, at least as of the end of 2017. Finally, although the study was done in the Western Cape, we believe that there is a high likelihood that the findings are generalisable to other provinces, given the national role of the Compensation Fund and the similar findings reported from other provinces. ${ }^{[9,11,14,17]}$

\section{Conclusions}

$\mathrm{TB}$ in health workers who work in a setting where they are exposed to patients with TB is legally a compensable occupational disease. However, the workers' compensation system, i.e. the whole process from reporting through to benefit provision, continues to be burdened with deficiencies. Health workers are not receiving the full compensation benefits rightfully due to them for occupational TB, and health workers who contracted TB describe their experience of the process in this regard as mostly negative.

Improvement in the administrative components of assisting employees with claim preparation and following up delays is required of the provincial employer, including better communication with employees and routine checking of claim status. Dedicated occupational health services are likely to improve the process for potential claimants, as well as serving as an important source of information about diagnosis and compensation aspects of TB among health workers in SA. However, without efficient and rapid resolution by the Compensation Fund of occupational disease claims, particularly those involving an acute illness phase, improvement in the submission process will bring little benefit to health workers.

Declaration. The research for this study was done in partial fulfilment of the requirements for NvdW's MMed (Occupational Medicine) degree at the University of Cape Town.

Acknowledgements. We thank the interviewers, Ms Natasha Kannemeyer and Ms Suzanne Human, for their dedication in collecting interview data, Ms Tanya van de Water for all her support and assistance in the collection and analysis of data, and the colleagues in the WCDH (Dr Tony Hawkridge, Mr Dean Kannemeyer and Mr Sakkie van Niekerk) who made this study possible through co-operation across different directorates within the department.

Author contributions. The subject was conceived by RE and planned by all the authors. NvdW finalised the proposal, oversaw data collection, completed the analysis and drafted the manuscript. All authors contributed to the final manuscript.
Funding. Funding for this study was provided by the Canadian Institutes of Health Research (CIHR) through grant ROH115212.

Conflicts of interest. None.

1. Grobler L, Mehtar S, Dheda K, et al. The epidemiology of tuberculosis in health care workers in South Africa: A systematic review. BMC Health Serv Res 2016;16:416. https://doi.org/10.1186/s12913-0161601-5

2. O’Donnell MR, Jarand J, Loveday M, et al. High incidence of hospital admissions with multidrugresistant and extensively drug-resistant tuberculosis among South African health care workers. Ann resistant and extensively drug-resistant tuberculosis among South African health care work
Intern Med 2010;153(8):516-522. https://doi.org/10.7326/0003-4819-153-8-201010190-00008

3. Tudor $C$, van der Walt ML, Margot B, et al. Occupational risk factors for tuberculosis among healthcare Tudor C, van der Walt ML, Margot B, et al. Occupational risk factors for tuberculosis among healthcare
workers in KwaZulu-Natal, South Africa. Clin Infect Dis 2016;62(Suppl 3):S255-S261. https://doi.

4. South Africa. Schedule 3 under the Compensation for Occupational Injuries and Disease Act South Africa. Schedule 3 under the Compensation for Occupational Injuries and Disease Act,
1993 as amended. Government Gazette No. 263012:552. 30 April 2004. http://www.labour.gov.za/ DocumentCenter/Pages/Acts.aspx?RootFolder=\%2FDocumentCenter\%2FActs\%2FCompensation $\% 20$ for\%20Occupational\%20Injuries\%20and\%20Diseases\%2FAmendments\&FolderCTID $=0$ x0120000D DC8879A7E263428976D08ED0489147\&View=\%7B4BE6BA1C\%2DC2AE\%2D49BB\%2D9B7A\%2D2 DB60BF41544\%7D (accessed 24 March 2020).

5. Ehrlich R, van de Water N, Yassi A. Tuberculosis as an occupational disease. Anthropol South Afr 2018;41(4):309-322. https://doi.org/10.1080/23323256.2018.1539624

6. South Africa. Compensation for Occupational Injuries and Disease Act No. 130 of 1993 (as amended 1997). Government Gazette No. 18430:1517. 14 November 1997. http://wwwlabour.gov.za/ DocumentCenter/Pages/Acts.aspx?RootFolder=\%2FDocumentCenter\%2FActs\%2FCompensation\%20 for\%20Occupational\%20Injuries\%20and\%20Diseases\&FolderCTID $=0$ x0120000DDC8879A7E263428 976D08ED0489147\& \&iew=\%7B4BE6BA1C\%2DC2AE\%2D49BB\%2D9B7A\%2D2DB60BF41544\%7D (accessed 24 March 2020).

. Ehrlich R. Persistent failure of the COIDA system to compensate occupational disease in South Africa. S Afr Med J 2012;102(2):95-97.

8. Goodman KC, Rees D, Arkles RS. Compensation for occupational lung disease in non-mining industry S Afr Med 1994;84(3):160-164.
So

S Afr Med 1994;84(3):160-164.
9. South African Society of Occupational Medicine (SASOM). Report on Workman's Compensation in South African Society of Occupational Medicine (SASO
Crisis Summit. Occup Health South Afr 2013;19(3):28-29.

10. Ehrlich RI, Adams S, Manjra S, Mokoena T, Jeebhay MF. Fate of outstanding COIDA occupational disease claims following closure of the Western Cape Provincial Medical Advisory Panel in 2008 - an audit. Occup Health South Afr 2015;21(6):6-10.

1. Naidoo $\mathrm{S}$. Compensation reporting of occupationally acquired TB in health care workers in public sector hospitals, eThekwini Municipality, KwaZulu-Natal. Occup Health South Afr 2006;July/August:3-7.

12. Onwuchekwe U, Ehrlich R, Jeebhay M, et al. Failure of the compensation system for occupational diseases and injuries. Occup Health South Afr 2002;8:8-11.

3. Jeebhay MF, Omar F, Kisting S, Edwards D, Adams S. Outcome of worker's compensation claims submitted by the Workers' Clinic in Cape Town. Occup Health South Afr 2002;8(1):4-7.

4. Carman H, Fourie A. The problem of compensation for occupational skin disease in South Africa. Occup Health South Afr 2010;16(5):12-21.

15. Public Protector of South Africa. Report on a systematic investigation into allegations of poor service delivery by the Compensation Fund. Report No. 28 of 2009/10. Part 1. 2010.

16. Public Protector of South Africa. Report on a systematic investigation into allegations of poor service delivery by the Compensation Fund. Report No. 28 of 2009/10. Part 2. 2010.

17. Rose A, Rees D. The impact of contact dermatitis: A case series from the National Institute for Rose A, Rees D. The impact of contact dermatitis: A case series from
Occupational Health (NIOH). Occup Health South Afr 2014;20(2):11-17.

18. Lewis P. The slow privatisation of a workers' compensation. GroundUp, August 2015. https://www

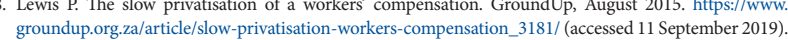
Mardon P. 800 of our members still waiting for their workers' comp - Solidarity. Politicsweb, 3 September 2015. https://www.politicsweb.co.za/news-and-analysis/800-of-our-members-still-waiting-for-their-workers (accessed 14 September 2019).

20. Department of Labour, South Africa. Circular instruction No. 178. Regarding compensation for pulmonary tuberculosis in health care workers. Government Gazette 2003, No. 24321:81

21. O’Hara NN, Roy L, O'Hara LM, et al. Healthcare worker preferences for active tuberculosis case finding programs in South Africa: A best-worst scaling choice experiment. PLoS One 2015;10:e0133304. https:/ doi.org/10.1371/journal.pone.0133304

22. Padayatchi N, Daftary A, Moodley T, Madansein R, Ramjee A. Case series of the long-term psychosocial impact of drug-resistant tuberculosis in HIV-negative medical doctors. Int J Tuberc Lung Dis 2010;14(8):960-966.

23. Von Delft A, Dramowski A, Khosa C, et al. Why healthcare workers are sick of TB. Int J Infect Dis 2015;32:147-151. https://doi.org/10.1016/j.ijid.2014.12.003

24. Nathavitharana RR, Bond P, Dramowski A, et al. Agents of change: The role of healthcare workers in the prevention of nosocomial and occupational tuberculosis. Presse Med 2017;46 (2 pt 2):e53-e62. https:// doi.org/10.1016/j.lpm.2017.01.014

25. Naidoo A, Naidoo S, Gathiram A, Lalloo U. Tuberculosis in medical doctors - a study of personal experiences and attitudes. S Afr Med J 2013;103(3):176-180. https://doi.org/10.7196/SAMJ.6266

26. Sommerland N, Wouters E, Masquillier C, et al. Stigma as a barrier to the use of occupational health . Sommerland N, Wouters E, Masquillier C, et al. Stigma as a barrier to the use of occupational health
units for TB services in South Africa. Int J Tuberc Lung Dis 2017;21(11):75-80. https://doi.org/10.5588/ units for TB servitl.17.0030

27. Siegel J, Yassi A, Rau A, et al. Workplace interventions to reduce HIV and TB stigma among health care workers - where do we go from here? Glob Public Health 2015;10(8):995-1007. https://doi.org/10.1080 $/ 17441692.2015 .1021365$

28. \#UnmaskStigma Initiative 2017. TB Proof, Cape Town. http://www.tbproof.org/wp-content/ uploads/2017/07/UnmaskStigma-Report-2017.docx.pdf (accessed 15 June 2019).

29. Zinatsa F, Engelbrecht M, van Rensburg AJ, Kigozi G. Voices from the frontline: Barriers and strategies to improve tuberculosis infection control in primary health care facilities in South Africa. BMC Health Ser Res 2018;18(1):269. https://doi.org/10.1186/s12913-018-3083-0

30. Weng Y-H, Bhembe PT, Chiou H-Y, Yang C-Y, Ya-Wen Chiu Y-W. Perceived risk of tuberculosis infection among healthcare workers in Swaziland. BMC Infect Dis 2016;16:697. https://doi.org/10.1186/s12879016-2029-6

31. Parent SN, Ehrlich R, Baxter V, Kannemeyer N, Yassi A. Participatory theatre and tuberculosis: A feasibility study with South African health care workers. Int J Tuberc Lung Dis 2018;21(2):140-148. https://doi.org/10.5588/ijtld.16.0399

32. TB Online Training Tool SD. TB Proof, Cape Town. http://www.tbproof.org/areyoutbproof/ (accessed 15 June 2019).

Accepted 3 October 2019 